Article

\title{
Interactions between a Buffered Amine Oxide Impregnation Carrier and an Acrylic Resin, and Their Relationship with Moisture
}

\author{
Simon Pepin ${ }^{1, *}$, Pierre Blanchet ${ }^{1,2}$ a and Véronic Landry ${ }^{1,2}(\mathbb{C}$ \\ 1 Natural Sciences and Engineering Research Council of Canada (NSERC) Industrial Chair on \\ Eco-Responsible Wood Construction, Université Laval, 2425 Rue de l'Université, \\ Québec, QC G1V 0A6, Canada; Pierre.Blanchet@sbf.ulaval.ca (P.B.); veronic.landry@sbf.ulaval.ca (V.L.) \\ 2 NSERC/Canlak Industrial Research Chair in Interior Wood-Product Finishes, Université Laval, 2425 Rue de \\ l'Université, Québec, QC G1V 0A6, Canada \\ * Correspondence: simon.pepin.1@ulaval.ca
}

Received: 18 March 2020; Accepted: 3 April 2020; Published: 7 April 2020

\begin{abstract}
Wood used outdoor is subjected to different sources of degradation and should be protected properly. In this study, acrylic resins were added to a wood impregnation system using amine oxides and propiconazole, an organic fungicide, to create a two-part wood protection preservation treatment. Since amine oxides can diffuse readily into wood, this treatment protected both the surface and inner structure of the treated wood following a simple dipping. Many aspects of the treatment were studied: the adhesion of the acrylic coatings, their permeability to water, and the impregnation depth of the propiconazole. In each case, a particular attention was accorded to the interactions between the resins and the impregnation system. Adhesion and permeability tests were coupled with an artificial aging process simulating severely wet conditions. Amine oxides reduced the adhesion of the coatings but did not impair their aging properties. Because of their hydrophilic nature, they also increased the permeability to liquid water, although they did not affect the air moisture permeability. The penetration of the propiconazole, estimated with a dye, decreased with the resin. Overall, the two parts of the treatment lightly impaired each other, but the practical aspect of this treatment may overcome these disadvantages.
\end{abstract}

Keywords: acrylic coating; amine oxides; propiconazole; wood protection; adhesion; permeability; impregnation; artificial aging; white pine; white spruce

\section{Introduction}

Wood used outdoors is exposed to many sources of degradation. Each of these sources (UV, moisture, decay fungi, wind, dust, etc.) bring their own contribution to the degradation, but they can also interact together [1,2]. Moisture is one of the most important agents of wood degradation, as it provokes dimensional changes, allows the growth of decay fungi and molds, promotes the leaching of wood treatments and water-soluble wood compounds, and so forth. After an extended period, the dimensional changes will make the wood warp, crack, and lose its coating, exposing unprotected wood to environmental hazards and hastening its degradation $[3,4]$.

Unlike wood used indoor, where humidity is usually lower and more effectively controlled, wood exposed outdoor is subject to a vast range of moisture conditions (dry periods, wet periods, rain, snow) [5]. These variations in humidity are the source of the dimensional changes, as they influence the moisture content of the wood, which shrinks and swells accordingly [3]. In order to reduce its degradation, wood must therefore be treated with preservatives and good building designs must be encouraged [5]. Impregnation treatments with different resins (phenolic, amino, silane, acrylic) can 
mitigate the intake of liquid water, but protection against air moisture is mainly achieved through wood modification (acetylation, esterification, thermal treatments, etc.) [6-10]. When a moisture content above $20 \%$ is reached, decay fungi can develop and feast on the wood cell materials, changing its mechanical and chemical properties [11]. A great diversity of organic and inorganic biocides can be impregnated to prevent the biodegradation from decay fungi and mold, such as triazoles, copper oxides and carbonates, borates, and quaternary compounds [12-14]. Impregnation treatments are often carried out in autoclaves, where methods employing vacuum and/or pressure can be used to ease the treatments into the wood structure $[15,16]$.

To effectively protect the surface of wood, diverse coatings can be used. They can be waterborne or solvent borne, usually contain an alkyd or acrylic resin, and have different levels of transparency $[5,17,18]$. They can also contain various nanocomponents, such as nanoparticles, nanoclays and nanoxides, to improve their properties (resistance to weathering and decay, hydrophobicity, UV absorption, fire-proofing, etc.) [19-21]. Because of the increasingly strict legislations surrounding vocs (volatile organic compounds), the use of solvent-based coatings is decreasing to prioritize waterborne formulations [22]. The latter are much more permeable, but have better aging properties and a higher flexibility [23-25]. This last point is crucial, as it allows them to follow the dimensional changes of wood without failing [26]. Alkyd resins lead to a better wetting and a deeper penetration into the wood substrate than acrylic resins, which increases their mechanical anchoring and improves their adhesion. However, acrylics are more flexible, lose less flexibility while aging, and allow better exchanges of moisture, which makes them overall more durable $[27,28]$.

In this study, an acrylic resin was added to an aqueous wood impregnation treatment to allow for the impregnation and priming of wood in a single step. Because of its porous nature, it is essential for wood to be primed, as it will fill its voids and improve the adhesion of the subsequent coats [29]. The impregnation system uses buffered amine oxides to promote the diffusion of an organic fungicide, propiconazole, into the wood following a simple dip, avoiding the use of pressure. The amine oxides solubilize the propiconazole in the aqueous solution and promote its penetration into the wood [30]. They also grant additional antiseptic properties to the treatment and improve the dimensional stability of the treated wood, while being non-toxic to both humans and the environment [31-34]. The gain in dimensional stability delays the cracking of the treated wood and the failing of its coating, while the impregnation of the propiconazole imbues resistance to decay fungi. Using a borate buffer $(\mathrm{pH}=8)$ improves the impregnation depth of both the amine oxides and the propiconazole, as well as the stability of the acrylic resin $[22,35,36]$.

The aim of the study was to monitor the relationship between the impregnation system and the acrylic resin, as well as their interactions with moisture. First, the influence of the hydrophilic amine oxides on the coating was investigated with permeability trials, to both liquid water and air moisture [25]. As surfactants, the amine oxides may also affect the wetting and film-formation of the acrylic resins, as well as some physical properties of the dry film. The adhesion of the coating was therefore evaluated, before and after artificial aging, to study the effect of the amine oxides on its tensile strength. Finally, the influence of the coating on the impregnation depth of the propiconazole was estimated by measuring the impregnation depth of an indigo blue dye.

\section{Materials and Methods}

\subsection{Materials}

Three acrylic resins, Encor ${ }^{\circledR}$ 627, Encor ${ }^{\circledR}$ DT 100, and Encor ${ }^{\circledR}$ 657, were purchased from Arkema Coating Resins (Cary, NC, USA). N,N-dimethyldodecylamine N-oxide (approximatively $30 \%$ in water) and an indigo dye (synthetic, 95\%) were obtained from Sigma-Aldrich Co. (St. Louis, MO, USA). Sodium tetraborate $(98 \%)$ was bought from Thermo Fisher Scientific (Ottawa, Canada), and ACS-grade ortho-boric acid was obtained from Anachemia (Mississauga, Canada). A commercial propiconazole formulation (Tilt 250E, 25\% aqueous solution) was generously supplied by Syngenta (Plattsville, 
Canada). N,N-dimethylhexadecylamine $\mathrm{N}$-oxide was synthetized and dissolved in a $30 \%$ aqueous solution, as described in [37].

Eastern white pine (Pinus strobus L.) and white spruce (Picea glauca Moench (Voss)), two common wood species for construction in Canada, were used in this study. Planks of both species were stored in a conditioning room at $20 \pm 2{ }^{\circ} \mathrm{C}$ and $65 \% \pm 5 \%$ relative humidity (RH) to reach a constant moisture content of $12 \%$. They were then planed into samples of several dimensions (Table 1 ) on the same day as they were treated in order to minimize the degradation of the surface. The samples were all free of knots and visible stain and contained only sapwood.

Table 1. Dimensions of the wood samples for the different tests.

\begin{tabular}{ccccc}
\hline \multirow{2}{*}{ Test } & \multicolumn{3}{c}{ Dimensions $(\mathbf{m m})$} & \multirow{2}{*}{ Repetitions } \\
\cline { 2 - 4 } & Longitudinal & Radial & Tangential & \\
\hline Water permeability & 20 & 20 & 20 & 5 \\
Sorption isotherm & 5 & 5 & 5 & 3 \\
Adhesion & 60 & 5 & 60 & 10 \\
Impregnation depth & 30 & 30 & 30 & 6 \\
\hline
\end{tabular}

\subsection{Treatments}

Samples were treated following a modified version of the method presented in previous studies $[36,37]$. The samples were dipped in hot $\left(65^{\circ} \mathrm{C}\right)$ treatment solutions for $15 \mathrm{~s}$ and left in the laboratory to dry for a day, followed by an additional six days in the conditioning room. The plastic wrap from the previous method was avoided to prevent its contact with the wet film, while the conditioning chamber was discarded as it seemingly did not bring any benefit.

The aqueous treatment solutions were prepared following a factorial design with buffered amine oxides conditions and acrylic resins conditions as the factors (Table 2). They could contain amine oxides and a borate buffer, or neither of them. The two amine oxides used were dimethyldodecylamine $\mathrm{N}$-oxide (DDAO) and dimethylhexadecylamine $\mathrm{N}$-oxide (DHAO), and the buffer was composed of boric acid and sodium tetraborate. They could also contain one of the three selected acrylic resins, or none. The acrylic resins were selected for their similar glass transition temperature, but different particle sizes $\left(0.1 \mu \mathrm{m}, 0.23 \mu \mathrm{m}\right.$, and $0.3 \mu \mathrm{m}$ for Encor ${ }^{\circledR} 627$, DT 100, and 657, respectively). The particle size of a resin affects different properties of the solution and dry film, similar to the viscosity and the penetration of the solution, and the adhesion of the film [5,38]. All the solutions contained either an indigo blue dye, for the impregnation depth test, or propiconazole, for all the other tests.

Table 2. Configuration and identification of the treatments.

\begin{tabular}{ccc}
\hline Acrylic Resin & Amine Oxide Condition & Identification \\
\hline No resin & No amine oxide/buffer (AO0) & R0-AO0 \\
$($ R0 $)$ & DDAO + buffer (AO1) & R0-AO1 \\
& 0.25 DDAO:0.75 DHAO + buffer (AO2) & R0-AO2 \\
Encor ${ }^{\circledR} 627$ & No amine oxide/buffer (AO0) & R1-AO0 \\
$(\mathrm{R} 1)$ & DDAO + buffer (AO1) & R1-AO1 \\
& 0.25 DDAO:0.75 DHAO & R1-AO2 \\
Encor ${ }^{\circledR}$ DT 100 & No amine oxide/buffer (AO0) & R2-AO0 \\
$($ R2 $)$ & DDAO + buffer (AO1) & R2-AO1 \\
& 0.25 DDAO:0.75 DHAO & R2-AO2 \\
Encor ${ }^{\circledR} 657$ & + buffer (AO2) & R3-AO0 \\
$($ R3 $)$ & No amine oxide/buffer (AO0) & R3-AO1 \\
& Only DDAO + buffer (AO1) & R3-AO2 \\
\hline
\end{tabular}


The treatment solutions with amine oxides contained $46.67 \mathrm{~g}$ of the $30 \%$ amine oxide solutions (14 $\mathrm{g}$ of $\mathrm{AO}$ ) and $1.75 \mathrm{~g}$ of both boric acid and sodium tetraborate. The solutions with an acrylic resin were prepared by adding the appropriate amount of resin to reach the final resin content desired. The resin content of each solution was chosen to obtain a dry film thickness around $50 \mu \mathrm{m}$ and was determined with preparatory essays following the standard ASMT D5235-18 [39]. Because thicker films were obtained from the solutions with Encor ${ }^{\circledR}$ DT 100, the resin content was adjusted accordingly. Every solution contained $5.6 \mathrm{~g}$ of Tilt $250 \mathrm{E}$ ( $1.4 \mathrm{~g}$ of propiconazole). Water was added to bring the solutions to a total mass of $700 \mathrm{~g}$. For the impregnation depth test, $100 \mathrm{~g}$ of the same solutions were prepared, where propiconazole was replaced with indigo. The experimental procedure of the study is described in Figure 1, the composition of the treatments is shown in Table 3, and the treatments used for each test are found in Table 4.

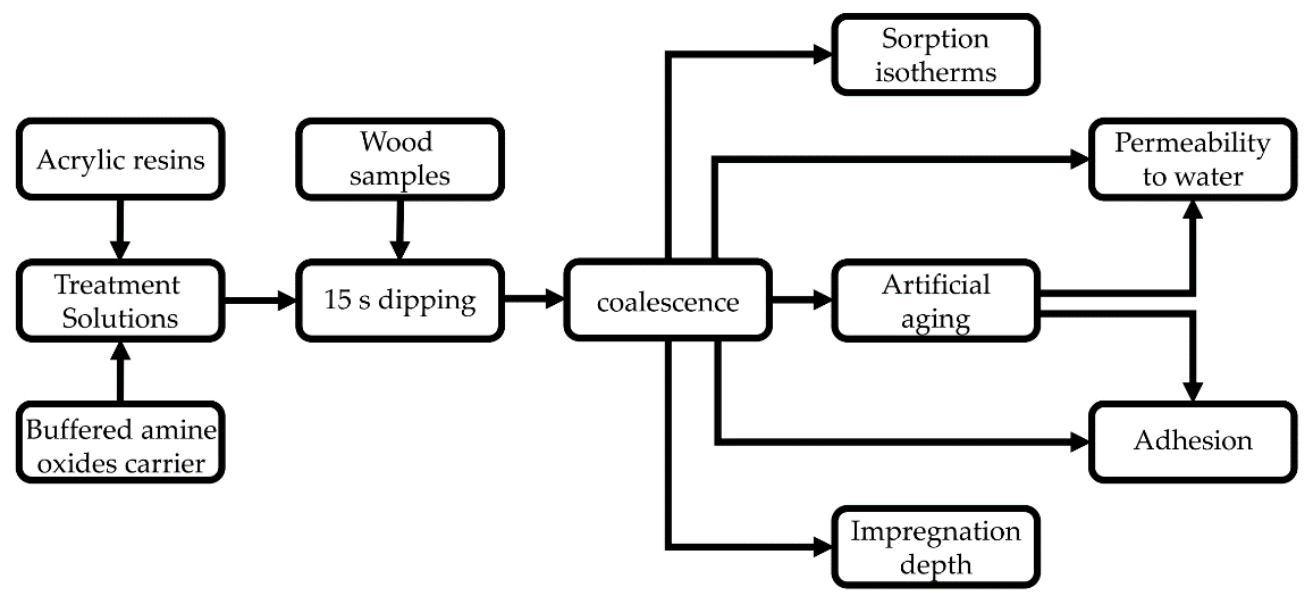

Figure 1. Experimental procedure of the study.

Table 3. Proportion (in \%) of the different chemicals in the treatments.

\begin{tabular}{lcccccccc}
\hline Treatment & Borate Buffer & DDAO & DHAO & $\begin{array}{c}\text { Encor }^{\circledR} \\
\mathbf{6 2 7}\end{array}$ & $\begin{array}{c}\text { Encor }^{\circledR} \\
\text { DT } \mathbf{~ 1 0 0}\end{array}$ & $\begin{array}{c}\text { Encor } \\
{ }^{\circledR}\end{array}$ & Prop. $^{\mathbf{1}} / \mathbf{I n d i g o}$ & $\mathbf{H}_{\mathbf{2}} \mathbf{O}^{\mathbf{2}}$ \\
\hline R0-AO0 & - & - & - & - & - & - & 0.2 & 99.8 \\
R0-AO1 & 0.5 & 2 & - & - & - & - & 0.2 & 97.3 \\
R0-AO2 & 0.5 & 0.5 & 1.5 & - & - & - & 0.2 & 97.3 \\
R1-AO0 & - & - & - & 40 & - & - & 0.2 & 59.8 \\
R1-AO1 & 0.5 & 2 & - & 40 & - & - & 0.2 & 57.3 \\
R1-AO2 & 0.5 & 0.5 & 1.5 & 40 & - & - & 0.2 & 57.3 \\
R2-AO0 & - & - & - & - & 40 & - & 0.2 & 59.8 \\
R2-AO1 & 0.5 & 2 & - & - & 35 & - & 0.2 & 62.3 \\
R2-AO2 & 0.5 & 0.5 & 1.5 & - & 30 & - & 0.2 & 67.3 \\
R3-AO0 & - & - & - & - & - & 40 & 0.2 & 59.8 \\
R3-AO1 & 0.5 & 2 & - & - & - & 40 & 0.2 & 57.3 \\
R3-AO2 & 0.5 & 0.5 & 1.5 & - & - & 40 & 0.2 & 57.3
\end{tabular}

${ }^{1}$ Prop. $=$ propiconazole ${ }^{2}$ Includes the mass of water and possible co-solvents contained in the formulations and solutions employed.

Previous penetration tests showed that the impregnation of the treatment is quite limited, especially perpendicularly to the grain [36]. It may therefore not be advised to extrapolate the results from this study to wood specimens of different dimensions. 
Table 4. Treatments that were used in each test.

\begin{tabular}{ccccc}
\hline Treatment & Permeability to Water & Sorption Isotherm & Adhesion & Impregnation Depth \\
\hline R0-AO0 & YES & - & - & - \\
R0-AO1 & YES & YES & - & YES \\
R0-AO2 & YES & - & - & YES \\
R1-AO0 & YES & Pine only & YES & - \\
R1-AO1 & YES & - & YES & YES \\
R1-AO2 & YES & - & YES & YES \\
R2-AO0 & YES & Pine only & YES & - \\
R2-AO1 & YES & - & YES & YES \\
R2-AO2 & YES & - & YES & YES \\
R3-AO0 & YES & YES & YES & - \\
R3-AO1 & YES & YES & YES & YES \\
R3-AO2 & YES & - & YES & YES \\
\hline
\end{tabular}

\subsection{Permeability to Moisture}

The permeability to liquid water of the acrylic coatings was tested according to the standard ASTM D5401-03 [40]. Immediately after being weighted, the samples were individually placed in $100 \mathrm{~mL}$ beakers with $70 \mathrm{~mL}$ of de-ionized water $\left(23^{\circ} \mathrm{C} \pm 2{ }^{\circ} \mathrm{C}\right)$. After $15 \mathrm{~min}$, they were turned over and soaked for an additional $15 \mathrm{~min}$. The samples were wiped dry and weighted again. The water repellent efficiency (WRE) was calculated as:

$$
\operatorname{WRE}(\%)=\frac{(\text { Mua }- \text { Mub })-(\text { Mta-Mtb })}{\text { Mua-Mub }} \times 100,
$$

where $\mathrm{M}_{\mathrm{ua}}$ and $\mathrm{M}_{\mathrm{ub}}$ represent the mass (in grams) of untreated samples after and before soaking, and $\mathrm{M}_{\mathrm{ta}}$ and $\mathrm{M}_{\mathrm{tb}}$ the mass (in grams) of treated samples after and before soaking, respectively. This test was performed on samples artificially aged for 14 cycles and unaged samples.

The air moisture permeability was investigated with sorption isotherms obtained with a DVS Adventure water vapor sorption analyzer (Surface Measurement Systems, Allentown, PA, USA). The oven-dried samples were exposed to increasing $(5 \%, 20 \%, 40 \%, 60 \%, 80 \%, 95 \% \pm 0.1 \%)$, then decreasing $(80 \%, 60 \%, 40 \%, 20 \%$, and $5 \% \pm 0.1 \%)$ relative humidity levels at a constant temperature of $25^{\circ} \mathrm{C} \pm 0.02{ }^{\circ} \mathrm{C}$. For each level, both the equilibrium moisture content (EMC) and the time needed to reach the EMC were considered. The equilibrium was reached when the mass of the sample changed by less than $0.003 \%$ within $5 \mathrm{~min}$.

\subsection{Adhesion}

The tensile strength of the coatings was tested according to the standard ASTM D4541-17 [41]. After lightly sanding the surface of the samples and dollies $(r=20 \mathrm{~mm})$, the surface of the dollies was washed with an acetone-soaked paper towel. The dollies were coated with an even layer of two-part LePage marine epoxy adhesive (Henkel, Mississauga, Canada) and glued to the sanded coating by applying as much pressure as possible with the thumb. A $\frac{3}{4}-10$ steel hex nut $(\mathrm{m}=79 \mathrm{~g})$ was placed on each dolly to keep a constant pressure for $48 \mathrm{~h}$. The coating and excess adhesive around the dollies were cut and the tensile strength was measured with a QTest Elite 5-kN electromechanical press (MTS, Eden Prairie, MN) exerting a perpendicular pull rate of $2 \mathrm{~mm} / \mathrm{min}$. The tensile strength was tested on unaged samples, as well as samples aged for 1, 7, and 14 cycles.

\subsection{Artificial Aging}

The artificial aging aimed to simulate magnified daily weather conditions (hot and dry summer days followed by cold and wet nights, winter) and expose the samples to cyclic variations of moisture to damage the wood-coating bonds (Table 5). The aging process was performed in an environmental test 
chamber (Envirotronics, Grand Rapids, MI, USA). Rain was simulated with four mist nozzles connected to the de-ionized water system $\left(\mathrm{T}=23 \pm 2{ }^{\circ} \mathrm{C}\right)$ of the institution, which produced both mist moisture and rain through condensation. More time was allotted to humid conditions, as preparatory essays showed that the samples dried much faster than they wetted. Moreover, Hoeflaak and Gard emphasized the importance of moisture during artificial aging, as the leaching of water-soluble compounds in the wood and the dry film influence the final properties of the coating [25]. UV radiations were not employed as the aim of the study was to investigate the sole effect of moisture on the treatment. Furthermore, as the coating is only meant to be a primer, it can be assumed that a topcoat with pigments or UV absorbers would block the UV radiations. After aging, the samples were placed in the conditioning room for a week.

Table 5. Conditions of one cycle of artificial aging.

\begin{tabular}{cccc}
\hline Conditions & Temperature $\left({ }^{\circ} \mathrm{C}\right)$ & Relative Humidity & Duration \\
\hline Rainy night & $5{ }^{\circ} \mathrm{C}$ & $98 \%+$ rain & $10 \mathrm{~h}$ \\
\hline Cold night & $5{ }^{\circ} \mathrm{C}$ & $98 \%$ & $22 \mathrm{~h}$ \\
\hline Winter & $-15{ }^{\circ} \mathrm{C}$ & $\mathrm{N} / \mathrm{A}$ & $8 \mathrm{~h}$ \\
Dry day & $50{ }^{\circ} \mathrm{C}$ & $20 \%$ & $8 \mathrm{~h}$ \\
\hline
\end{tabular}

\subsection{Impregnation Depth}

The impregnation depth of the propiconazole was visually estimated with an indigo blue dye. Although the penetration depth of the two chemicals is not expected to be exactly the same, the use of a dye with a similar structure to propiconazole should allow a practical and reliable method to study the distribution of the fungicide into wood. Samples with dimensions $30 \mathrm{~mm} \times 30 \mathrm{~mm} \times 30 \mathrm{~mm}$ were treated with solutions containing the indigo dye instead of propiconazole. They were then cut to $15 \mathrm{~mm} \times 15 \mathrm{~mm} \times 15 \mathrm{~mm}$ from one of the corners to view the impregnation in the three principal planes (Figure 2). The penetration of the dye was observed with an Olympus SZ61 stereomicroscope (Tokyo, Japan) with a 40× magnification and measured with a Velmex micrometer (Bloomfield, NY. USA) to a $\pm 2 \mathrm{~mm}$ precision.

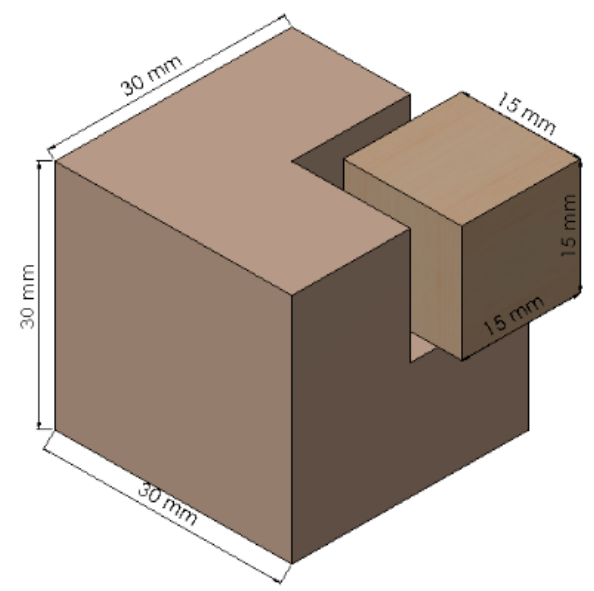

Figure 2. Dimensions of the treated sample and of the section selected for analysis.

\subsection{Statistics}

The liquid water permeability and adhesion tests followed an amine oxide*acrylic resin*aging three-factors factorial design. The impregnation depth was analysed with an amine oxide*acrylic resin two-factors factorial design. The analysis of variance (ANOVA) was performed with the SAS University software (SAS, Cary, NC, USA) by using the mixed procedure at $p=0.05$. The effects were considered significant at $p<0.05$ and very significant at $p<0.01$. 


\section{Results and Discussion}

\subsection{Properties of the Treatments}

Table 6 shows some properties of the treatment solutions and dry coatings used during this study. Although many elements of the acrylic resins and their formulations are unknown, such as the constituting monomers, the degree of polymerisation, the stabilizing surfactants, and the additives, these properties will explain many observations throughout the different tests. The viscosity of the solutions without a resin was evaluated with a VISCOlab 4000 viscometer (Cambridge Viscosity, Boston, MA, USA), while the viscosity of the solutions with a resin was evaluated with a byko-visc DS rotational viscometer (BYK-Gardner, Columbia, MD, USA). The film thickness was measured on a longitudinal-radial face of the liquid permeability test samples (after the test) according to the standard ASTM D5235-18 [39]. The dying time was obtained following the 7.2 procedure of the ASTM D1640-14 standard [42] on $75 \mathrm{~mm} \times 38 \mathrm{~mm} \times 1 \mathrm{~mm}$ glass slides (EMS, Hatfield, PA, USA) in the laboratory $\left(\mathrm{T}^{\mathrm{O}}=20^{\circ} \mathrm{C}, \mathrm{RH}=13 \%\right)$. The glass transition temperatures $(\mathrm{Tg})$ were obtained by differential scanning calorimetry (DSC) with a Mettler Toledo DSC823 ${ }^{\mathrm{e}}$ (Mississauga, Canada) using the STARe analysis software.

Table 6. Properties of the treatment solutions (at $65^{\circ} \mathrm{C}$ ) and of the dry coatings.

\begin{tabular}{|c|c|c|c|c|c|c|c|}
\hline \multirow{2}{*}{ Treatment } & \multirow{2}{*}{$\begin{array}{l}\text { Viscosity } \\
\text { (cP) }\end{array}$} & \multicolumn{2}{|c|}{$\begin{array}{c}\text { Film Thickness } \\
(\mu \mathrm{m})\end{array}$} & \multirow{2}{*}{$\begin{array}{c}\text { Drying Time } \\
\text { (s) }\end{array}$} & \multirow{2}{*}{$\begin{array}{l}\text { Theorical } \\
\mathrm{Tg} *\left({ }^{\circ} \mathrm{C}\right)\end{array}$} & \multirow{2}{*}{$\begin{array}{c}\text { Experimental } \\
\operatorname{Tg}\left({ }^{\circ} \mathrm{C}\right)\end{array}$} & \multirow{2}{*}{$\begin{array}{l}\text { Particle Size * } \\
(\mu \mathrm{m})\end{array}$} \\
\hline & & Pine & Spruce & & & & \\
\hline R0-AO1 & 0.77 & N/A & N/A & N/A & N/A & N/A & N/A \\
\hline R0-AO2 & 6.47 & N/A & N/A & N/A & N/A & N/A & N/A \\
\hline $\mathrm{R} 1-\mathrm{AO} 2$ & 91 & 88.5 & 62.5 & 375 & 15 & 5.06 & 0.10 \\
\hline R2-AO0 & 32 & 40.5 & 49.5 & 165 & 20 & 14.69 & 0.23 \\
\hline R2-AO1 & 66 & 53.5 & 47.5 & 114 & 20 & 11.34 & 0.23 \\
\hline $\mathrm{R} 2-\mathrm{AO} 2$ & 164 & 62.0 & 83.5 & 2344 & 20 & 8.96 & 0.23 \\
\hline R3-AO0 & 27 & 55.5 & 55.3 & 130 & 14 & 11.55 & 0.30 \\
\hline
\end{tabular}

* These properties are provided by the supplier of the acrylic resins.

The DHAO from AO2 dramatically increased the viscosity of the solutions. It is attributable to its longer aliphatic chain, which favors the formation of rod-like micelles instead of spherical/ellipsoidal micelles, as in the case of DDAO [43-46]. Rod-like micelles entangle with each other, which causes their solutions to be much more viscous and viscoelastic than other micelle shapes [47-49]. Coincidently, the dry films from the more viscous solutions were typically thicker. It is perfectly coherent with the direct relationship between the thickness of a dry film and the thickness of its preceding wet film. Obviously, the more viscous solutions left thicker wet film layers after the dipping, which resulted in thicker dry films. While AO1 did not increase the viscosity of its solution without acrylic resins (R0-AO1), it did increase the viscosity of the solutions containing the acrylic resins. Some surfactants can interact with the hydrophobic parts of the polymers [50]. These interactions provoke the swelling of the polymer network, leading to an increased viscosity of the solution [51]. This phenomenon is particularly observed with ionic surfactants [52], while amine oxides are non-ionic under a basic $\mathrm{pH}$. It is however possible that the amine oxides could act as ionic because of their zwitterionic nature.

The glass transition temperatures ( $\mathrm{Tg}$ ) were different from the values provided by the supplier, even for the films without amine oxides. It may be caused by the presence of propiconazole into the films, or simply by the method of analysis employed. It is however obvious that the amine oxides notably reduced the $\mathrm{Tg}$ of the coatings. During the evaporation of water, surfactants can migrate following different patterns. They can form a distinctive layer at the air/coating and coating/wood 
interfaces, make hydrophile pockets into the film, or blend into the polymer [53,54]. These patterns depend on many elements, including the rate of water evaporation, the solubility of the surfactants in water, and the affinity of the surfactants with the polymer [55]. During this study, the wet films dried very quickly, most likely because of the dry conditions of the laboratory, which favored the blending of the amine oxides into the dry film. Furthermore, when the solutions are heated at a temperature beyond the Tg of the polymer, which was the case during this study, the polymer particles become softer [56]. The hydrophobic tail of the non-ionic surfactants stabilizing their surface will then partly penetrate into the particles, increasing even more their presence into the dry film. The presence of surfactants in a coating have a plasticizing effect, which affects its $\mathrm{Tg}$. The magnitude of the $\mathrm{Tg}$ variation depends on the affinity of the polymer and the surfactants, which is determined by the HLB (hydrophile-lipophile balance) of the latter [57]. In this case, it can be estimated that the lipophilic character of the DHAO, which has a longer aliphatic chain $\left(\mathrm{C}_{16}\right)$, would be greater than that of the DDAO $\left(C_{12}\right)$. It should therefore have a better affinity with the hydrophobic acrylic resins, resulting in a lower $\mathrm{Tg}$ for $\mathrm{AO} 2$ than $\mathrm{AO} 1$.

\subsection{Permeability to Moisture}

The water repellent efficiency (WRE) of the treatments is shown in Figures 3 and 4. The WRE of the aged samples was calculated with the absorption of aged untreated samples. For samples treated without an acrylic resin, the amine oxides usually brought some hydrophobicity, particularly when treated with $\mathrm{AO} 2$, as it contains the longer and less polar DHAO. Likewise, while the amine oxides increased the permeability of the coatings, they were still less permeable under AO2 than AO1. Interestingly, although the acrylic coatings always had a high WRE on white spruce, R2 and R3 had negative to low WRE on white pine. While micro-CT scan analyzes did not show any structural differences between the permeable and impermeable coatings, optical microscopy showed gloss differences between these treatments. Unlike the other planes, transversal faces had very little gloss, as a result of the absorption of the coating into the wood cells (Figure 5). However, the coatings did not penetrate as easily into latewood, as the lumens are much smaller [58]. A coherent and impermeable layer could therefore form at the surface of the latewood, which can be seen by its gloss. Since white pine has quite larger latewood cells, treatments with R2 and R3 still penetrated into the lumens, decreasing its protection. This difference is meaningful, as latewood is much more permeable than earlywood $[59,60]$. The inability to protect latewood correctly therefore resulted in a much higher water absorption for these treatments but may be improved with a second layer of coating.

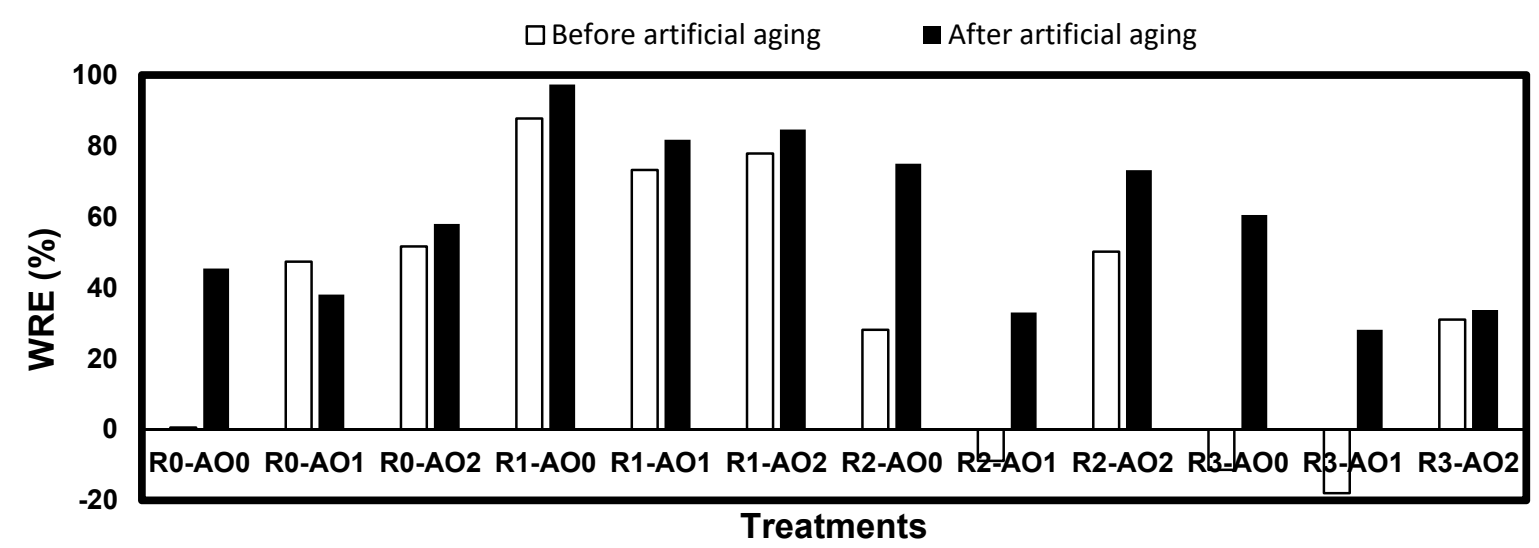

Figure 3. Water repellent efficiency (WRE) of the white pine before and after artificial aging. 


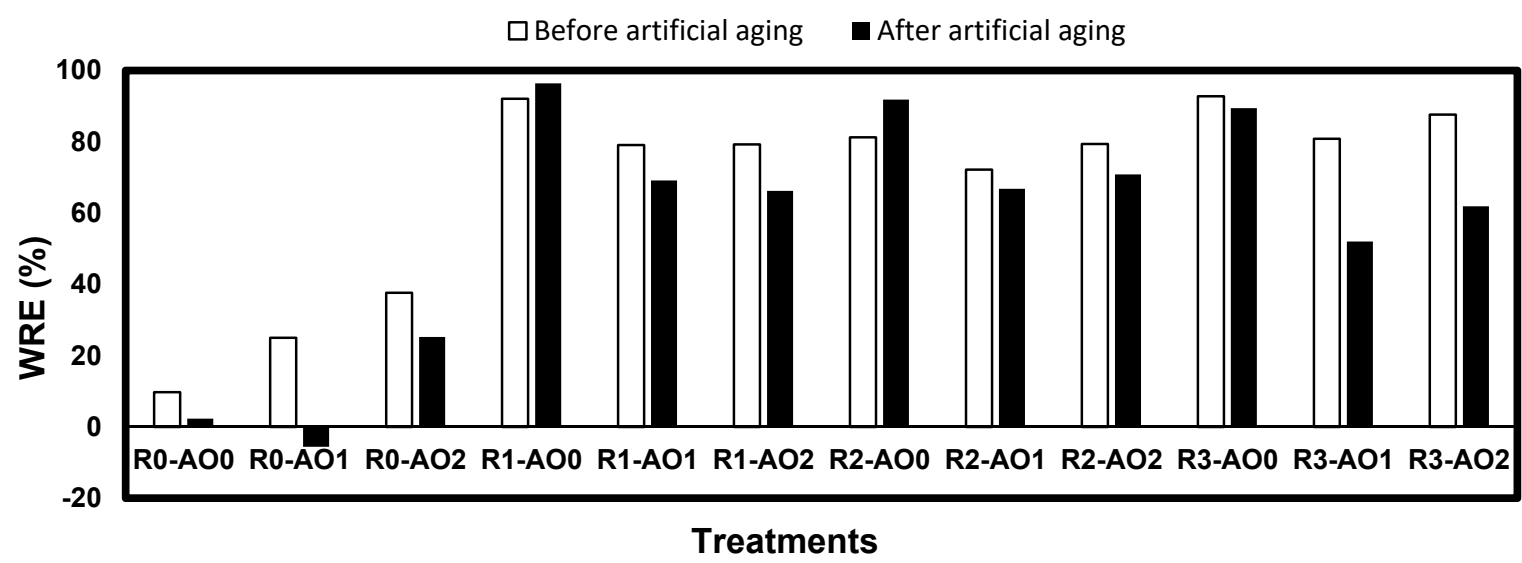

Figure 4. Water repellent efficiency (WRE) of the white spruce before and after artificial aging.
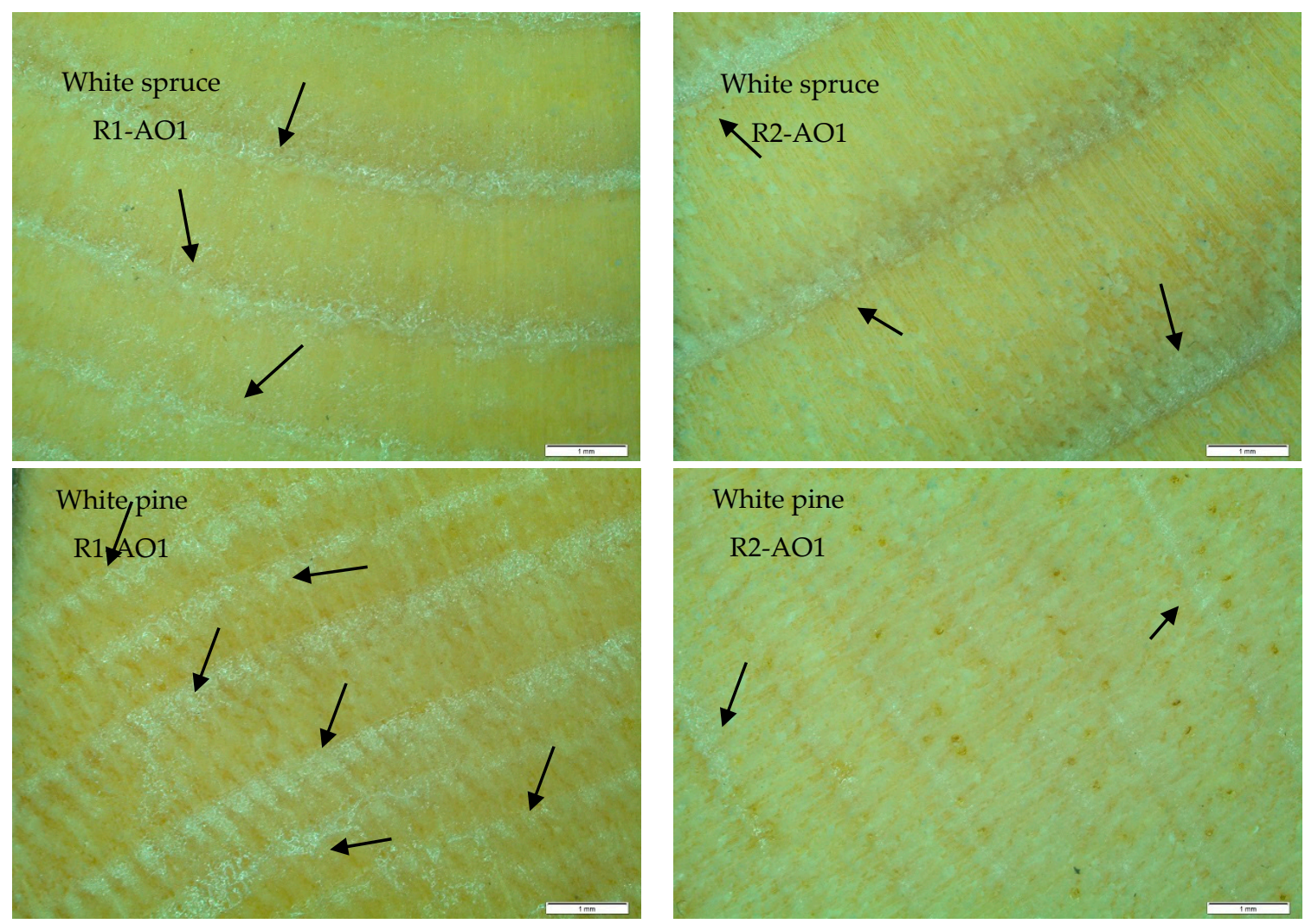

Figure 5. Optical microscopy of the transverse plane of white spruce and white pine treated with $\mathrm{R} 1-\mathrm{AO} 1$ and R2-AO1. The arrows indicate the presence of resin at the surface of the latewood.

The WRE of the white pine increased after the artificial aging, showing a slower increase in permeability for the treated samples than for the untreated samples. All the pine samples without an acrylic resin cracked, while R3-AO1 and R3-AO2 were the only coated samples to crack. Interestingly, in the case of the white spruce, all the samples with amine oxides cracked, with R3-AO1 and R3-AO2 being very damaged. Since the white pine samples treated with R2-AO1 did not crack while being much more permeable than the white spruce samples, the cracking may not be entirely attributable to dimensional changes. The expansion of water into the wood during the freezing periods may have caused additional stresses which promoted the damages. To further support this hypothesis, it may be noted that the cracks on the coated samples were often more numerous and larger than on the uncoated samples, particularly for R3-AO1 and R3-AO2. Most of the water in the lumen of the uncoated samples may have left during the $22 \mathrm{~h}$ high relative humidity period preceding the freezing period, while it was 
trapped in the less permeable coated samples. Coincidently, more ice formed in the latter, producing more stresses. White spruce may have suffered more damages than white pine as it is denser (density $=0.337 \mathrm{~g} / \mathrm{cm}^{3}$ and $0.322 \mathrm{~g} / \mathrm{cm}^{3}$ for white spruce and white pine, respectively), leaving less room for the ice to expand.

It is unknown why pine samples treated without amine oxides and acrylics (R0-A0) were so impermeable after the artificial aging. It may however explain why, in a previous study, pine treated under these conditions were much more dimensionally stable than untreated pine [37].

The statistical analysis of the WRE (Table 7) has shown that the acrylic resin*amine oxides interaction was very significant. Having an hydrophilicity between that of wood and the acrylic resins, the amine oxides brought some hydrophobicity to the uncoated wood (R0), but also made the hydrophobic acrylic resins more hydrophilic [54,61]. Therefore, in the former, they increase the WRE compared to samples without amine oxides, while in the latter, they reduce it.

Table 7. F ratio and $p$ values of the statistical analyzes for the permeability test.

\begin{tabular}{|c|c|c|c|c|}
\hline \multirow[t]{2}{*}{ Factor/Interaction } & \multicolumn{2}{|c|}{ White Pine } & \multicolumn{2}{|c|}{ White Spruce } \\
\hline & $\mathbf{F}$ & $p$ & $\mathbf{F}$ & $p$ \\
\hline Amine oxides & 164.41 & $<0.0001^{* *}$ & 73.40 & $<0.0001 * *$ \\
\hline Acrylic resin & 642.70 & $<0.0001^{* *}$ & 1009.15 & $<0.0001^{* *}$ \\
\hline Aging & 565.28 & $<0.0001 * *$ & 121.63 & $<0.0001^{* *}$ \\
\hline Amine oxides*Acrylic resin & 66.92 & $<0.0001^{* *}$ & 40.37 & $<0.0001^{* *}$ \\
\hline Amine oxides*Aging & 87.92 & $<0.0001^{* *}$ & 37.61 & $<0.0001^{* *}$ \\
\hline Acrylic resin*Aging & 59.24 & $<0.0001^{* *}$ & 19.17 & $<0.0001^{* *}$ \\
\hline Amine oxides*Acrylic resin*Aging & 25.32 & $<0.0001^{* *}$ & 2.71 & $0.0181 *$ \\
\hline
\end{tabular}

The acrylic resin*aging interaction was also very significant, particularly in white pine $(\mathrm{F}=59.24)$, since most coated samples resisted cracking. This led to large increases of their WRE after aging, particularly in R2 and R3, as their WRE was very low before aging. In the case of white spruce, the interaction comes from the large decrease of WRE in R3-AO1 and R3-AO2 after aging, which were much more cracked than samples treated with the same amine oxides conditions under R1 and R2.

The amine oxides*aging interaction was also very significant for both species. In the case of white pine, it is attributable to the massive increase in WRE of R0-AO0 and R3-AO0 after aging, when compared to the same acrylic resins with amine oxides. As mentioned earlier, it is not understood why R0-AO0 became so impermeable, as nothing present in the treatment should improve its hydrophobicity, and that this behavior was not found in white spruce. The case of R3-AO0 is much easier to understand, as it simply did not crack, whereas R3-AO1 and R3-AO2 did crack. This simple difference allowed the former to improve its WRE much more than the others. In the case of the white spruce, all the samples treated with both an acrylic resin and amine oxides cracked, while samples treated with only an acrylic resin did not. Accordingly, the WRE of the samples treated with amine oxides decreased after aging, whereas it increased for the samples treated without.

The equilibrium moisture content (EMC) and time elapsed after reaching equilibrium of the sorption isotherms, as taken with the water vapor sorption analyzer, are shown in Figures 6 and 7 . As all the acrylic resins were expected to have a similar permeability, this test was initially performed only on the least viscous resin, R3. This criterion was prioritized to favor a uniform thickness of the coating on the very small samples used. However, since all the resins had different liquid permeabilities in white pine, they were all tested without amine oxides on that specie to investigate if their permeability to liquid water and air moisture were related. It was found that all the coated samples had similar EMCs, which was way below the EMC of the uncoated samples. It is explained by the mass of the coating, which increased the initial dry mass of the samples by about $50 \%$. Taking this detail into account, the mass of water absorbed actually becomes superior in the samples with a coating. Since acrylic coatings are hydrophobic, it can be estimated that only a small proportion of this water is contained 
into the coating, and that the EMC of the wood samples with and without coating may be comparable, which is consistent with the literature [62]. The water uptake of R3 was however particularly high for both species, showing a higher hydrophilia than the other resins.
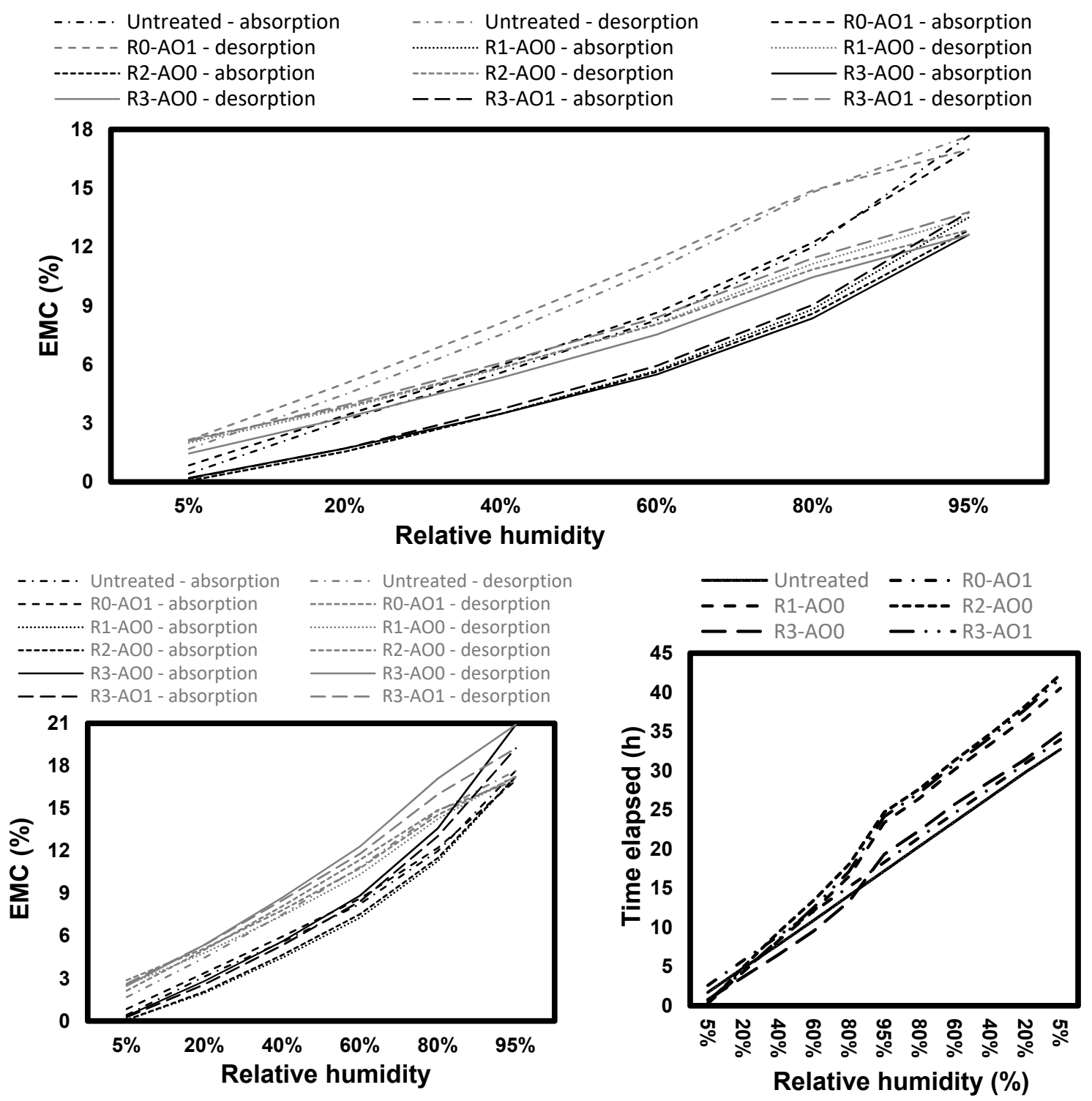

Figure 6. Equilibrium moisture content (EMC) of the samples before (top) and after removing the mass of the coatings (left), and time elapsed after reaching the equilibrium (right) at the different steps during the sorption isotherms in white pine.

While the coatings did not reduce the EMC, they did slow down the uptake of water, particularly at $95 \%$ RH. In average, each absorption step was about $1 \mathrm{~h}$ longer for coated pine samples than the uncoated ones, and 30 min longer in white spruce, whereas it was $4 \mathrm{~h}$ longer to reach equilibrium at $95 \%$ RH for both species. On the other hand, the rate of desorption was just slightly slower in the coated samples for both species. The only exception was treatment R3-AO0 on white pine, which absorbed and desorbed at the same rate as the uncoated samples, except at $80 \%$ and $95 \%$, showing an analogous behavior to its liquid permeability. 

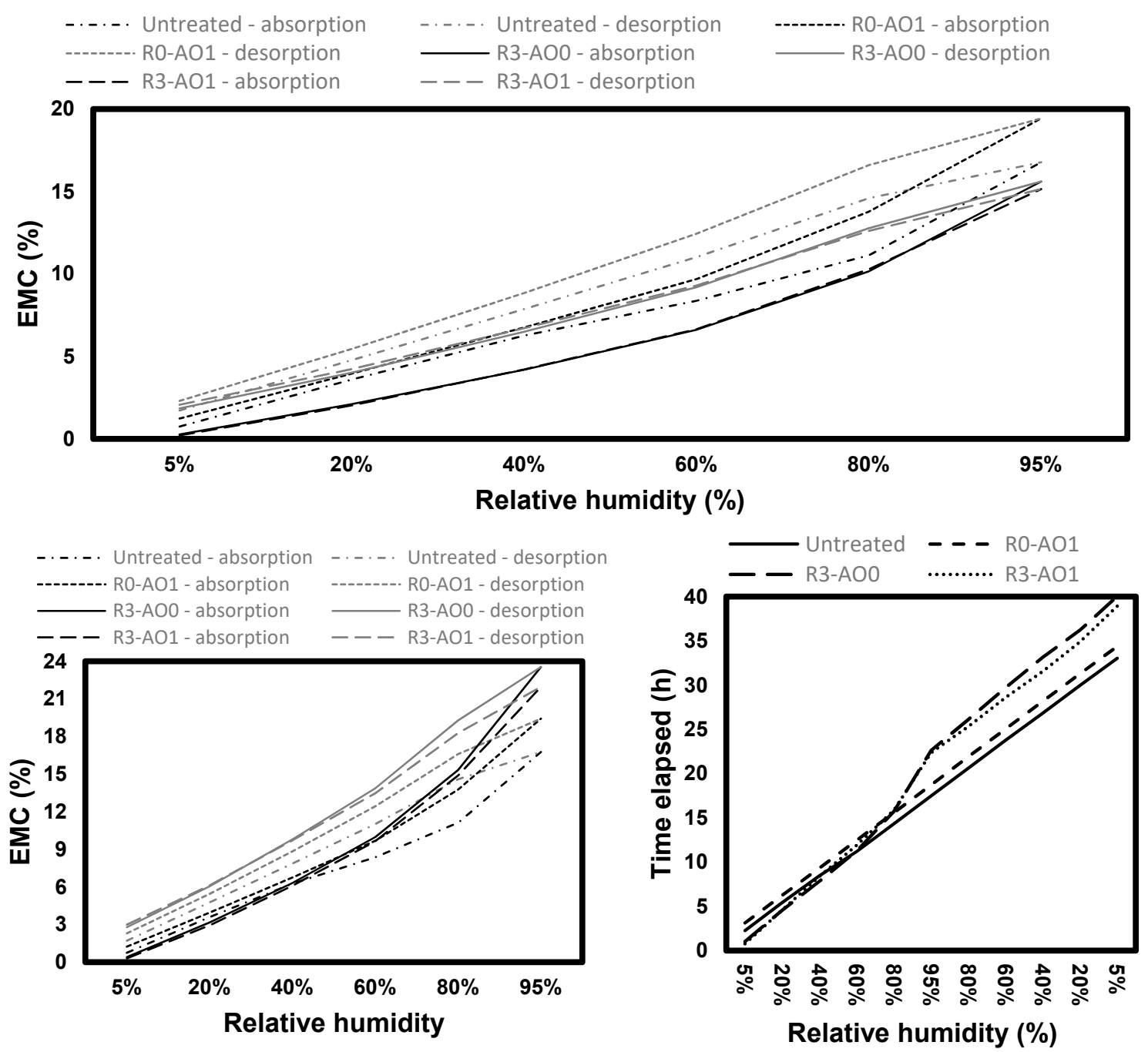

Figure 7. Equilibrium moisture content (EMC) of the samples before (top) and after removing the mass of the coatings (left), and time elapsed after reaching the equilibrium (right) at the different steps during the sorption isotherms in white spruce.

When treated with amine oxides only, the wood samples absorbed more water than the untreated samples. It may be caused by the ability of amine oxides to bind with up to eight water molecules through hydrogen bonds, which increases the number of available sites for water adsorption [63]. They however did not change the time required to attain equilibrium, hinting at a faster moisture uptake, although the water bound to amine oxides should not produce dimensional changes. When adding the amine oxides to R3, however, the EMC decreased, hinting a reduction of the coating's hydrophilia. This observation is in contradiction with the liquid permeability of the coating, but may suggest that the liquid water passing through the coating is not directly linked to the mass of water absorbed and retained by the coating itself. For example, the amine oxides may actually make the coating less hydrophilic, but increase its porosity. In the case of white spruce, the adsorption and desorption of water were slightly faster on R3-AO1 than R3-AO0 at low RH levels, but slower at high HR levels, leading in average to faster, but similar moisture exchanges. In the case of white pine, adding amine oxides to the permeable R3 slowed down the moisture exchanges rates to a pace comparable to the other coatings. These results are in contradiction with other workers, who found that the leaching of water-soluble compounds from a coating reduced its permeability to water vapor [25], meaning that these compounds actually increased the permeability. 
The difference of absorption rate between the coated and uncoated samples was higher than for the desorption rate. It means that the coatings blocks water more effectively when entering the wood than when leaving it. Consequently, while it does slightly prevent wood from gaining moisture, it does not prevent it from subsequently drying.

\subsection{Adhesion}

The tensile strength of the coatings after different artificial aging periods is shown in Figure 8. Given the slight differences between the samples aged for 0 and 14 cycles, it may seem as if the artificial aging process was too short or too gentle. However, several white pine samples treated with R1, under all the amine oxide conditions, had long cracks along the grain after 14 cycles. It suggests that the aging process did produce heavy dimensional changes in the samples, as the spruce samples would have cracked too if the expansion of ice had caused the damages. These performances should therefore be attributed to the flexibility and good aging properties of the acrylic resins [4,24]. It is however interesting that the samples treated with R1 were the only ones to crack, as this resin had the best WRE on white pine and never cracked on the permeability samples. The monitoring of the mass of some samples during the artificial aging however suggested that all the treatments reached the fiber saturation point $(\mathrm{MC}=30 \%)$, so dimensional changes may not be the only element at stake. Rather, some properties of the films may be responsible. For example, if the films from this acrylic resin were more rigid, the tensions in the films as the wood shrinks and swells would be greater than for the other resins. Since the samples are fairly thin and fragile, these tensions would add non-negligible stresses into the soft pine wood and provoke its cracking.
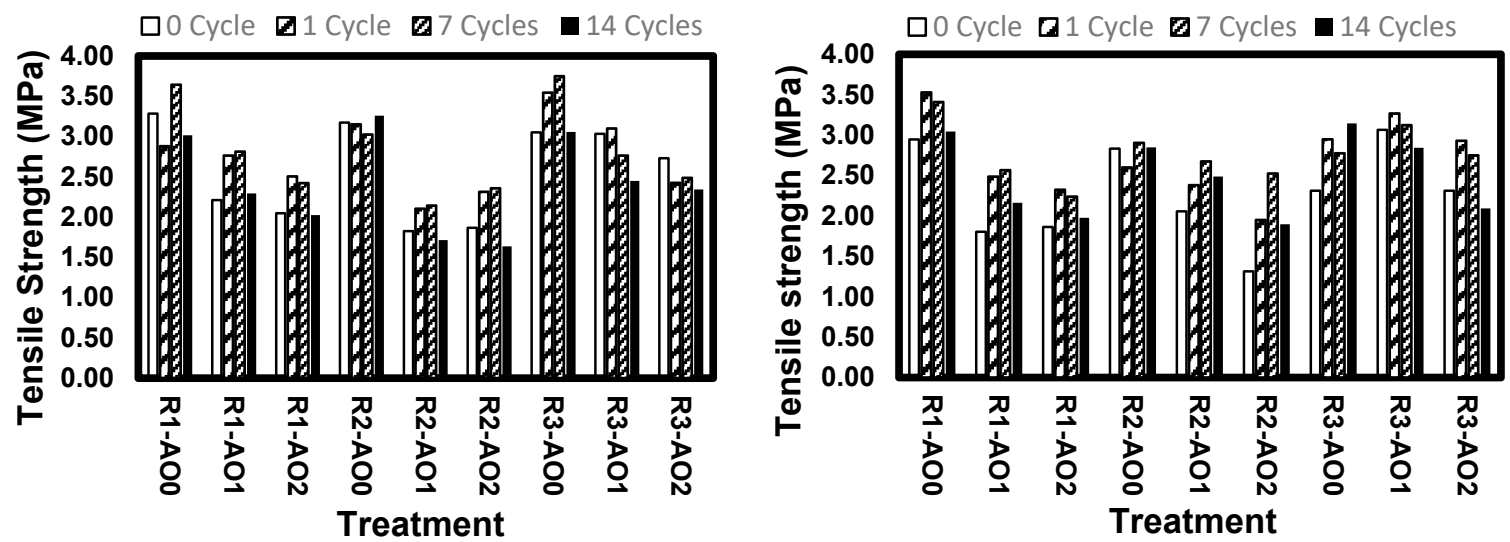

Figure 8. Tensile strength required to pull-off the dollies from white pine (left) and white spruce (right).

The adhesion results obtained were fairly low, since values as high as $9.2 \mathrm{mPa}$ were obtained by other workers with acrylic coatings on white spruce [64]. Two main reasons may explain these results. First, to simulate real-life industrial conditions, the samples were planed, as this is a common practice in the industry. However, planed surfaces have a very low adhesion, as the contact surface is much lower than for rougher surfaces [65]. Second, the coating did not penetrate radially into the wood, which limited its adhesion. The size of the particles may have been too large, as we used particles ranging from 100 to $300 \mathrm{~nm}$, while the radial pits of the wood are much smaller than that $60 \mathrm{~nm}$ when fully swollen) [60]. Baumstark and Tiarks recommended using acrylic particles way below $100 \mathrm{~nm}$ when coating wood [66]. Moreover, the application of the treatment through dipping does not apply any kind of force on the wet film to help its penetration, unlike methods such as painting or brushing.

The fracture was almost always at the wood/coating interface, although the treatments without amine oxides and R3-AO1 had some wood cohesion failure, as their tensile strengths were the highest. The only exceptions were some unaged $\mathrm{R} 2-\mathrm{AO} 2$ spruce samples, which had cohesion failure into the coating, as well as R2-AO1 pine samples, which had increasing amounts of epoxy glue at their surface after each aging period. For the former, since this treatment solution was very viscous and its dry film 
fairly thick, the evaporation of the solution and the coalescence of the coating near the wood/coating interface may have been compromised. In the case of R2-AO1, the bleeding of extractives from the white pines could have interfered with the adhesion of the film, which will be discussed below.

The statistical analysis (Table 8) showed that, for both species, the amine oxide*acrylic resin interaction was very significant, but for different reasons. In the case of white spruce, it is caused by the higher tensile strength of R3-AO1 in comparison to R3-AO0, while the other resins had the highest tensile strength under AO0. It could be explained by a relation between the tensile strength of the coatings and their $\mathrm{Tg}$. Indeed, while the $\mathrm{Tg}$ of $\mathrm{R} 1$ and $\mathrm{R} 2$ were decreased by the amine oxides, it was not the case for R3 (Table 6). Accordingly, while R3-AO1 had a higher Tg than R3-AO0, its tensile strength was also higher. This relationship is unusual, since the $\mathrm{Tg}$ of a coating usually reduces the flexibility of the film and increases the internal stresses, leading to an earlier fracture [67]. Felton et al. however found that it was not always the case, although they could not explain their observation [68]. In the case of white pine, the interaction is caused by the lower tensile strength of R2-AO1 compared to R2-AO2. White pine has a high extractives content and is known to undergo resin exudation, which impairs coatings performances [69]. During the aging process, brown stains appeared on the transversal faces of the pine samples treated with R2-AO1 and R2-AO2, suggesting that this acrylic resin is prone to extractives bleeding when paired with amine oxides. While no colored stains or resin accumulation were visible on the other faces of the samples, resins may still have affected the coatings, as white pine have both longitudinal and radial resin canals. Additionally, it was noted that, for samples aged for 7 and 14 cycles, small dots of epoxy glue would remain on the samples after the pull-off test. It strongly suggests that extractive compounds may have diffused through the coatings and interfered with the curing of the glue. While it is unknown if resin exudation or other extractives are responsible for the loss of tensile strength, it can be concluded that some molecules present in the white pine either interfered with the film formation of these treatments or blended into the film. Those compounds may be hydrophobic, as amine oxides were required to transport them. Since R2-AO1 was much more fluid than R2-AO2, it might have been more effective at allowing the diffusion of the compounds, hence why it was affected more severely.

Table 8. F ratio and $p$ values of the statistical analyzes for the adhesion test.

\begin{tabular}{ccccc}
\hline Factor/Interaction & \multicolumn{2}{c}{ White Pine } & \multicolumn{2}{c}{ White Spruce } \\
\hline & F & $p$ & F & $p$ \\
\hline Amine oxides & 195.68 & $<0.0001^{* *}$ & 130.27 & $<0.0001^{* *}$ \\
Acrylic resin & 47.38 & $<0.0001^{* *}$ & 41.85 & $<0.0001^{* *}$ \\
Aging & 17.31 & $<0.0001^{* *}$ & 34.45 & $<0.0001^{* *}$ \\
Amine oxides*Acrylic resin & 8.03 & $<0.0001^{* *}$ & 31.79 & $<0.0001^{* *}$ \\
Amine oxides*Aging & 1.78 & 0.1023 & 2.91 & $0.0089^{* *}$ \\
Acrylic resin*Aging & 1.57 & 0.1567 & 4.46 & $0.0002^{* *}$ \\
Amine oxides*Acrylic resin*Aging & 4.21 & $<0.0001^{* *}$ & 4.25 & $<0.0001^{* *}$ \\
\hline & ** shows $p<0.01$ &
\end{tabular}

For both species, the aging factor was very significant. After the first cycle of artificial aging, the tensile strength increased and stayed comparable up to the seventh cycle. The rapid loss of hydrophilic compounds under the wet conditions contributed to improve the tensile strength of the coatings [55]. Since the amine oxide*aging interaction was not significant in white pine, it suggests that the amine oxides are well fixated into the coatings and did not leach. Consequently, the compounds lost may be related to the acrylic resins, such as surfactants. These compounds add essential properties to the treatment solution, such as an increased stability and an eased film formation, but can in turn become detrimental into the dry film. After 14 cycles, the tensile strength had begun to decrease, which hints that at some point after the seventh cycle, the bonds between the coating and the wood began to break. From this point onward, it could therefore be expected that the adhesion would continuously decrease with more aging. 


\subsection{Impregnation Depth}

The impregnation depth of the indigo dye is shown in Figure 9. In the case of the white pine, the penetration of the indigo from the treatment solutions without a resin was fairly deep in the earlywood and slightly deeper in the latewood, while it only penetrated in the earlywood of the white spruce. This difference was attributed to the radius of the latewood tracheids of the two species [36]. Since the samples are impregnated without pressure, the capillary forces in the lumen become critical to allow the treatment solutions into the wood. The radius of the lumen, which is heavily connected to the capillary forces $\left(\mathrm{r}^{4}\right)$ [70], is much smaller in the white spruce than the white pine, and insufficient to allow the penetration of the solution. The deeper penetration in the latewood of the white pine than its earlywood was attributed to its thicker and stiffer cell walls, which reduce the nonlinear flow of the solution and the aspiration of the wood pits, allowing a deeper penetration $[59,60]$. No impregnation was observed perpendicularly to the grain, as the indigo loaded amine oxide micelles may be too large to penetrate the radial pits.

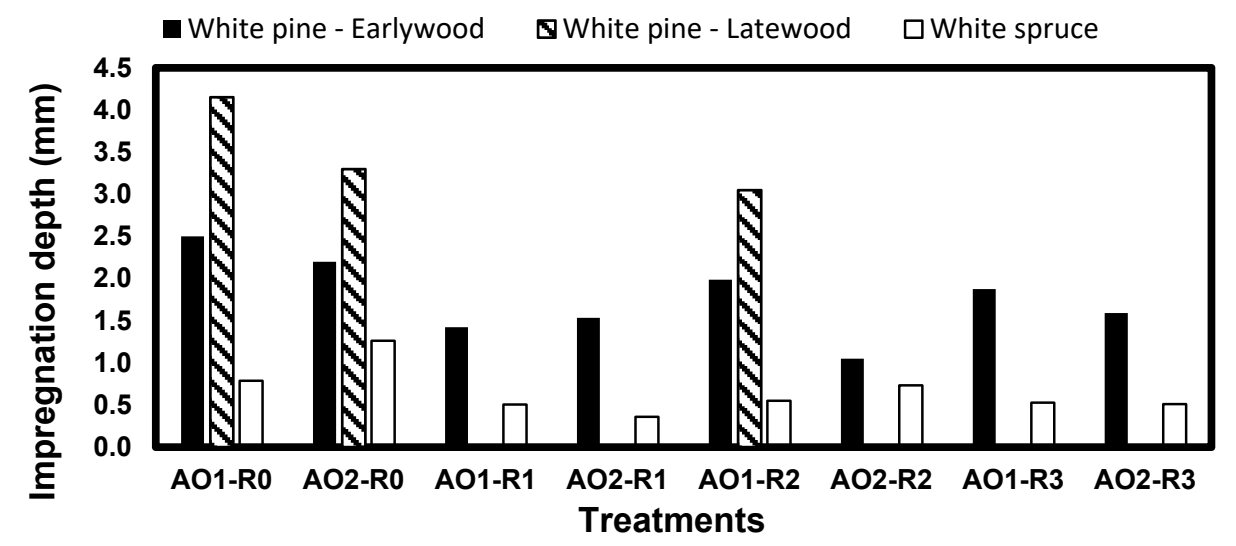

Figure 9. Impregnation depth of the indigo dye in the white pine (earlywood and latewood) and the earlywood of the white spruce.

The treatment solutions with a resin were much more viscous, which drastically reduced their penetration. Moreover, only one of those solutions could still penetrate the latewood of the white pine.

The statistical analysis (Table 9) showed that the two wood species reacted differently to the treatments. For both species, the amine oxide*resin interaction was very significant. The impregnation in the white pine was usually slightly shallower when using the amine oxides conditions $\mathrm{AO} 2$, while the difference was very important in the case of the R2. These results are intuitive, as they are closely correlated to the viscosity of the solutions (Table 6). Indeed, most treatments were only slightly more viscous under $\mathrm{AO} 2$ than $\mathrm{AO} 1$, while $\mathrm{R} 2-\mathrm{AO} 2$ was much more viscous than $\mathrm{R} 2-\mathrm{AO} 1$. The reason why $\mathrm{R} 2$ interacts so strongly with $\mathrm{AO} 2$ in comparison with the other resins cannot be explained with the limited information available about the acrylic resins. It is however clear that the penetration of the indigo dye (and most likely propiconazole) in the white pine is affected by capillarity, as the Washburn equation states that the penetration of a fluid in a capillary is inversely proportional to its viscosity [71]. In the case of the white spruce, the relation was much more complex, as every acrylic resin condition reacted differently. A hypothesis could be a relation between the drying time of the coatings and the impregnation depth of the indigo, as the impregnation depth seems to be inversely proportional to the drying time (Table 6). Since the lumens are much smaller in white spruce than white pine, which limits the impregnation, and that the coatings dried in only a few minutes, the impregnation depth may be limited by the amount of indigo dye penetrating into the wood before the film becomes impermeable. It however would not explain why R0-AO2 penetrated deeper than R0-AO1, as they did not contain a resin. 
Table 9. F ratio and $p$ value of the statistical analyzes for the impregnation depth test.

\begin{tabular}{|c|c|c|c|c|c|c|}
\hline \multirow[t]{2}{*}{ Factor/Interaction } & \multicolumn{2}{|c|}{ White Pine - Earlywood } & \multicolumn{2}{|c|}{ White Pine - Latewood } & \multicolumn{2}{|c|}{ White Spruce } \\
\hline & $\mathbf{F}$ & $p$ & $\mathbf{F}$ & $p$ & $\mathbf{F}$ & $p$ \\
\hline Amine oxides & 31.11 & $<0.0001 * *$ & 19.80 & $<0.0001 * *$ & 4.83 & $<0.0347^{*}$ \\
\hline Acrylic resin & 33.10 & $<0.0001^{* *}$ & 2585.77 & $<0.0001^{* *}$ & 63.81 & $<0.0001^{* *}$ \\
\hline Amine oxides*Acrylic resin & 14.60 & $<0.0001^{* *}$ & 19.80 & $<0.0001^{* *}$ & 15.28 & $<0.0001^{* *}$ \\
\hline
\end{tabular}

For the white pine (both earlywood and latewood), the amine oxides and resin factors were both very significant with high $\mathrm{F}$ values $(\mathrm{F}>30)$. Once again, viscosity is clearly a key factor here. In presence of the resins, the solutions even become too viscous to allow the impregnation of the latewood. The only exception is the solution R2-AO1, which also happens to have the deepest impregnation of the earlywood. It may illustrate that, while being crucial, the viscosity is not the only factor affecting the penetration of the dye. If the viscosity is very close to the critical viscosity enabling penetration into the latewood, an additive in the resin $\mathrm{R} 2$ may be sufficient to allow the dye into the latewood. Obviously, a deeper impregnation could be achieved by using pressure, particularly in the white pine. It would however be more hazardous because of the resins and would increase the process cost.

Combining the impregnation system (amine oxides and propiconazole) and acrylic resins was expected to change the properties of the different components, but some of the interactions observed were unforeseen. The most disappointing surprise was the reduction of adhesion of the coatings by the amine oxides. The adhesion is the most important property of a primer, as it is the only layer in contact with the substrate, and the lifespan of the whole coating depends on it [29]. Moreover, $\mathrm{AO} 2$, which was observed to grant the most dimensional stability [37], particularly decreased the adhesion. Rather, as surface-active agents, amine oxides were expected to increase the wettability of the acrylic resins, enhance their penetration and improve their adhesion. While it was expected that adding hydrophilic amine oxides to the coatings would increase their permeability to water [61], it was expected that the air moisture permeability would also increase [25], which was not the case. It is a very good feature, as wood can often be protected from rain by the building design. Consequently, the treatment could be used in many situations without affecting the permeability to water and causing additional dimensional changes. The liquid permeability tests however showed that, within only hours of being soaked, even the most impermeable treatments would exceed a moisture content of $20 \%$, allowing fungal degradation [11]. This does not come as a surprise, as water-based coatings are much more permeable, but it shows that the impregnation of a fungicide, such as propiconazole, is essential to preserve wood used outdoor. The various test samples were affected differently by the artificial aging, which is summarized in Table 10. 
Table 10. Effects of artificial aging on the adhesion and permeability samples.

\begin{tabular}{|c|c|c|c|}
\hline Test & Species & Effect & Explanation \\
\hline \multirow[b]{2}{*}{ Permeability } & White Pine & $\begin{array}{l}\text { Samples treated without resins } \\
\text { cracked, as well as those treated } \\
\text { with R3 and amine oxides. }\end{array}$ & \multirow{2}{*}{$\begin{array}{l}\text { A combination of the stresses } \\
\text { generated by the varying moisture } \\
\text { content (dimensional changes) and } \\
\text { the formation of ice during the } \\
\text { freezing period caused the cracking. } \\
\text { White spruce was particularly affected } \\
\text { as it is denser. }\end{array}$} \\
\hline & White Spruce & $\begin{array}{l}\text { Sample treated without resins, } \\
\text { or with a resin and amine oxides, } \\
\text { cracked. A mixture of } \mathrm{R} 3 \text { and } \\
\text { amine oxides led to the } \\
\text { most damages. }\end{array}$ & \\
\hline \multirow{4}{*}{ Adhesion } & \multirow{3}{*}{ White Pine } & $\begin{array}{l}\text { Samples treated with } \mathrm{R} 1 \text {, under } \\
\text { all the amine oxides } \\
\text { conditions, cracked }\end{array}$ & $\begin{array}{l}\text { As pine is soft and the samples were } \\
\text { thin, a higher tension caused by this } \\
\text { particular resin may have caused a } \\
\text { critical stress in the samples during } \\
\text { the dimensional changes. }\end{array}$ \\
\hline & & $\begin{array}{l}\text { Brown stains on the transversal } \\
\text { faces and epoxy glue curing } \\
\text { issues after seven cycles of aging } \\
\text { of R2-AO1 sample. }\end{array}$ & $\begin{array}{l}\text { White pine is prone to resin } \\
\text { exudation, causing brown stains on } \\
\text { wood coatings. The epoxy glue curing } \\
\text { issues may be caused by the diffusion } \\
\text { of extractive compounds through the } \\
\text { coating during the aging. }\end{array}$ \\
\hline & & $\begin{array}{l}\text { The tensile strength increased } \\
\text { after one cycle of aging but } \\
\text { decreased between the seventh } \\
\text { and } 14^{\text {th }} \text { cycle. }\end{array}$ & \multirow{2}{*}{$\begin{array}{l}\text { The rapid loss of water-soluble } \\
\text { compounds in the coatings may have } \\
\text { increased their Tg and improved their } \\
\text { adhesion after the first cycles. After } \\
\text { the seventh cycle, the bonds between } \\
\text { the wood and the coatings started to } \\
\text { break, decreasing the adhesion. }\end{array}$} \\
\hline & White Spruce & $\begin{array}{l}\text { The tensile strength increased } \\
\text { after one cycle of aging but } \\
\text { decreased between the seventh } \\
\text { and } 14^{\text {th }} \text { cycle. }\end{array}$ & \\
\hline
\end{tabular}

\section{Conclusions}

In this study, the addition of an acrylic resin to an impregnation system using amine oxides and propiconazole to protect wood, both inside and outside, through a simple dipping was performed, and their relationship to moisture was characterized. It was found that the amine oxides affected many properties of the treatment solutions and dry films. They increased the viscosity of the solutions and the film thickness, but decreased the glass transition temperature $(\mathrm{Tg})$ and drying time.

The amine oxides reduced the adhesion of the acrylic coatings, as a result of the decreased $\mathrm{Tg}$. The tensile strength of all the coatings obtained increased at the beginning of the artificial aging, and only started to decrease by the end of the aging period, showing good aging properties.

The amine oxides increased the permeability to liquid water of the coatings, but improved their permeability to air moisture in white pine, while not affecting white spruce. The use of amine oxides increased the cracking of white spruce, which was attributed to the freezing and thawing properties of this denser species.

The acrylic coatings reduced the impregnation depth of the indigo dye, which simulated the penetration of the propiconazole, as a result of the higher viscosity of the solutions. In the case of the white pine, it also prevented the impregnation of the late wood in most treatments.

Overall, the combination of the acrylic resins and impregnation system led to a small loss of performances for both parts. However, this acrylic coating is only a primer, and more coats could be added to improve its properties, such as its permeability. Therefore, with some optimization, this kind of wood treatments could represent an efficient and cheap way to impregnate and prime wood in a single step. It would improve the commercial competitivity of wood in the construction market by offering a durable product without affecting the production cost and time too much. 
Author Contributions: Conceptualization, methodology, validation, formal analysis, investigation, data curation, visualization, writing-original draft preparation, S.P.; project administration, funding acquisition, P.B. writing-review and editing, supervision, P.B. and V.L. All authors have read and agreed to the published version of the manuscript.

Funding: This research was funded by Natural Sciences and Engineering Research Council of Canada, grant numbers IRCPJ 461745- 18 and RDCPJ 524504-18.

Acknowledgments: The authors are grateful to Natural Sciences and Engineering Research Council of Canada for the financial support through its IRC and CRD programs (IRCPJ 461745- 18 and RDCPJ 524504-18) as well as the industrial partners of the NSERC industrial chair on eco-responsible wood construction (CIRCERB).

Conflicts of Interest: The authors declare no conflict of interest.

\section{References}

1. Feist, W.C. Outdoor Wood Weathering and Protection. In Archaeological Wood: Properties, Chemistry, and Preservation; Rowell, R.M., Barbour, R.J., Eds.; American Chemical Society: Washington, DC, USA, 1990; pp. 263-298. ISBN 9780841216235.

2. Cogulet, A.; Blanchet, P.; Landry, V. The Multifactorial Aspect of Wood Weathering: A Review Based on a Holistic Approach of Wood Degradation Protected by Clear Coating. BioResources 2018, 13, 2116-2138. [CrossRef]

3. Glass, S.V.; Zelinka, S.L. Physical Properties and Moisture Relations of Wood. In Wood Handbook; Wood as an Engineering Material (FPL-GTR-190); Ross, R.J., Ed.; U.S. Department of Agriculture Forest Products Laboratory: Madison, WI, USA, 2010.

4. Feist, W.C. Weathering Performance of Painted Wood Pretreated with Water-Repellent Preservatives. For. Prod. J. 1990, 40, 21-26.

5. Bulian, F.; Graystone, J.A. Industrial Wood Coatings, 1st ed.; Elsevier: Oxford, UK, 2009; ISBN 9780444528407.

6. Kumar, S. Chemical Modification Of Wood. Soc. Wood Sci. Technol. 1994, 26, 270-280.

7. Wang, C.; Piao, C. From Hydrophilicity to Hydrophobicity: A Critical Review - Part II: Hydrophobic Conversion. Wood Fiber 2010, 42, 490-510.

8. Yuan, J.; Hu, Y.; Li, L.; Cheng, F. The Mechanical Strength Change of Wood Modified with DMDHEU. BioResources 2013, 8, 1076-1088. [CrossRef]

9. Kocaefe, D.; Huang, X.; Kocaefe, Y. Dimensional Stabilization of Wood. Curr. For. Rep. 2015, 1, $151-161$. [CrossRef]

10. Reinprecht, L. Wood Deterioration, Protection, and Maintenance, 1st ed.; John Wileys \& Sons: Chichester, UK, 2016; ISBN 9781119106531.

11. Hill, C. Wood Modification: Chemical, Thermal and Other Processes; John Wileys \& Sons: Chichester, UK, 2006; ISBN 978-0-470-02172-9.

12. Schultz, T.; Nicholas, D. A Brief Overview of Non-Arsenical Wood Preservative Systems. In Wood Deterioration and Preservation: Advances in Our Changing World; Goodell, B., Nicholas, D.D., Schultz, T.P., Eds.; American Chemical Society: Washington, DC, USA, 2003; Volume 845, pp. 420-432. ISBN 9780841237971.

13. Laks, P.E. Wood Preservative Fungicides and the American Wood Preservers' Association Use Category System. In Development of Commercial Wood Preservatives; Schultz, T.P., Militz, H., Freeman, M.H., Goodell, B., Nicholas, D.D., Eds.; American Chemical Society: Washington, DC, USA, 2008; Volume 982, pp. 228-240. ISBN 978-0-8412-3951-7.

14. Ross, A.S. Organic Preservative Systems for the Protection of Wood Windows and Doors. In Development of Commercial Wood Preservatives; Schultz, T.P., Militz, H., Freeman, M.H., Goodell, B., Nicholas, D.D., Eds.; American Chemical Society: Washington, DC, USA, 2008; Volume 982, pp. 470-479. ISBN 978-0-8412-3951-7.

15. Leightley, L.E. Protection of Wood Using Combinations of Biocides. In Wood Deterioration and Preservation: Advances in Our Changing World; Goodell, B., Nicholas, D.D., Schultz, T.P., Eds.; American Chemical Society: Washington, DC, USA, 2003; Volume 845, pp. 420-432. ISBN 9780841237971.

16. Freeman, M.H. Wood Preservative Formulation Development and Systems: Organic and Inorganic Based Systems. In Development of Commercial Wood Preservatives; Schultz, T.P., Militz, H., Freeman, M.H., Goodell, B., Nicholas, D.D., Eds.; American Chemical Society: Washington, DC, USA, 2008; pp. 408-426. ISBN 978-0-8412-3951-7. 
17. Jewell, G.W. Latex Properties: Effect of Water Phase and Particle Size. In Surface Coatings: Volume 1 Raw Materials and Their Usage; Parsons, P., Ed.; Chapman \& Hall: London, UK, 1993; pp. 320-324. ISBN 978-94-011-1220-8.

18. de Meijer, M. Review on the Durability of Exterior Wood Coatings with Reduced VOC-Content. Prog. Org. Coat. 2001, 43, 217-225. [CrossRef]

19. Papadopoulos, A.N.; Taghiyari, H.R. Innovative Wood Surface Treatments Based on Nanotechnology. Coatings 2019, 9, 866:1-866:14. [CrossRef]

20. Taghiyari, H.R.; Tajvidi, M.; Taghiyari, R.; Mantanis, G.I.; Esmailpour, A.; Hosseinpourpia, R. Nanotechnology for Wood Quality Improvement and Protection. In Nanomaterials for Agriculture and Forestry Applications; Husen, A., Jawaid, M., Eds.; Elsevier: Amsterdam, The Netherlands, 2020; pp. 469-489. ISBN 978-0-12-817852-2.

21. Teng, T.-J.; Mat Arip, M.N.; Sudesh, K.; Nemoikina, A.; Jalaludin, Z.; Ng, E.-P.; Lee, H.-L. Conventional Technology and Nanotechnology in Wood Preservation: A Review. BioResources 2018, 13, 9220-9252. [CrossRef]

22. Müller, B.; Poth, U. Coatings Formulations, 2nd ed.; Vincentz Network: Hanover, Germany, 2011; ISBN 978-3-86630-891-6.

23. Hernández, R.E.; Cool, J. Evaluation of Three Surfacing Methods on Paper Birch Wood in Relation to Waterand Solvent-Borne Coating Performance. Wood Fiber Sci. 2008, 40, 459-469.

24. Miller, E.R.; Boxall, J. Water-Borne Paints for Exterior Wood. Pigment Resin Technol. 1984, 13, 15. [CrossRef]

25. Hoeflaak, M.; Gard, W.F. Test Methods for a Reliable Assessment of Water-Borne Paints for Exterior Wood Protection. Surf. Coat. Int. Part B Coat. Int. 2001, 84, 259-262. [CrossRef]

26. Probst, B.F.; Laborie, M.P.; Pizzi, A.; Merlin, A.; Deglise, X. Molecular Mechanics / Experimental Methods Applied to Varnish / Primer / Wood Interactions. Holzforschung 1997, 51, 459-466. [CrossRef]

27. Bardage, S.L.; Bjurman, J. Adhesion of Waterborne Paints to Wood. J. Coat. Technol. 1998, 70, 39-47. [CrossRef]

28. Bonura, T.; Bussjeager, S.; Christensen, L.; Daisey, G.; Daniels, T.; Hirsch, M.; Jourdain, C.J.; Mall, D.D.; Springate, B.; Wagner, L.E.; et al. Finishes Checklist: A Guide to Achieving Optimum Coating Performance on Exterior Wood Surfaces. JCT CoatingsTech 2004, 1, 36-49.

29. Nussbaum, R.M. Penetration of Water-Borne Alkyd Emulsions and Solvent-Borne Alkyds into Wood. Holz als Roh und Werkst. 1994, 52, 389-393. [CrossRef]

30. Shen, S.; Walker, L.E. Methods for Enhancing Penetration of Wood Preservatives. Patent WO2000059696A2, 2001.

31. Tseng, C.-I.; Walker, L.E.; Kempinska, C. Compositions Comprising a Boron Compound and an Amine Oxide. Patent WO2002001958A2, 2002.

32. Tseng, C.-I.; Walker, L.E. Azole/Amine Oxide Wood Preservatives. Patent WO2000071314A1, 2000.

33. Sanderson, H.; Tibazarwa, C.; Greggs, W.; Versteeg, D.J.; Kasai, Y.; Stanton, K.; Sedlak, R.I. High Production Volume Chemical Amine Oxides [C8-C20] Category Environmental Risk Assessment. Risk Anal. 2009, 29, 857-867. [CrossRef]

34. Sanderson, H.; Counts, J.L.; Stanton, K.L.; Sedlak, R.I. Exposure and Prioritization-Human Screening Data and Methods for High Production Volume Chemicals in Consumer Products: Amine Oxides a Case Study. Risk Anal. 2006, 26, 1637-1657. [CrossRef]

35. Ross, A.S.; Cutler, K.A. Method of Employing Enhanced Penetration of Wood Preservatives to Protect Wood and a Related Solution. U.S. Patent 20120258248A1, 2014.

36. Pepin, S.; Blanchet, P.; Landry, V. Characterization of the Diffusion of Organic Fungicides with Amine Oxides in White Pine and White Spruce. BioResources 2020, 15, 1026-1049.

37. Pepin, S.; Blanchet, P.; Landry, V. Performances of White Pine and White Spruce Treated with Organic Fungicides Using an Aqueous Buffered Amine Oxide Preservation System. BioResources 2019, 14, $264-288$. [CrossRef]

38. Revillon, A.; Lacaze, P.-C. Manuel Des Peintures et Vernis-Volume 1-Constituants Des Peintures et Vernis; Éditions Hermann: Paris, France, 2005; ISBN 978-2705665661.

39. ASTM D5235-18. Standard Test Method for Microscopic Measurement of Dry Film Thickness of Coatings on Wood Products; ASTM International: West Conshohocken, PA, USA, 2018. [CrossRef]

40. ASTM D5401-03. Standard Test Method for Evaluating Clear Water Repellent Coatings on Wood; ASTM International: West Conshohocken, PA, USA, 2014. [CrossRef] 
41. ASTM D4541-17. Standard Test Method for Pull-Off Strength of Coatings Using Portable Adhesion; ASTM International: West Conshohocken, PA, USA, 2018. [CrossRef]

42. ASTM D1640-14. Standard Test for Drying, Curing, or Film Formation of Organic Coatings; ASTM International: West Conshohocken, PA, USA, 2018. [CrossRef]

43. Nagarajan, R. Molecular Packing Parameter and Surfactant Self-Assembly: The Neglected Role of the Surfactant Tail. Langmuir 2002, 18, 31-38. [CrossRef]

44. Lorenz, C.D.; Hsieh, C.M.; Dreiss, C.A.; Lawrence, M.J. Molecular Dynamics Simulations of the Interfacial and Structural Properties of Dimethyldodecylamine-N-Oxide Micelles. Langmuir 2011, 27, 546-553. [CrossRef]

45. Herrmann, K.W. Micellar Properties and Phase Separation in Dimethyldodecylamine Oxide-Sodium Halide-Water Systems. J. Phys. Chem. 1964, 68, 1540-1546. [CrossRef]

46. Kakehashi, R.; Yamamura, S.; Tokai, N.; Takeda, T.; Kaneda, K.; Yoshinaga, K.; Maeda, H. Hydrogen Ion Titration of Long Alkyl Chain Amine Oxide Micelles. J. Colloid Interface Sci. 2001, 243, 233-240. [CrossRef]

47. Yang, J. Viscoelastic Wormlike Micelles and Their Applications. Curr. Opin. Colloid Interface Sci. 2002, 7, 276-281. [CrossRef]

48. Brinchi, L.; Germani, R.; Di Profio, P.; Marte, L.; Savelli, G.; Oda, R.; Berti, D. Viscoelastic Solutions Formed by Worm-like Micelles of Amine Oxide Surfactant. J. Colloid Interface Sci. 2010, 346, 100-106. [CrossRef]

49. Kalur, G.C.; Frounfelker, B.D.; Cipriano, B.H.; Norman, A.I.; Raghavan, S.R. Viscosity Increase with Temperature in Cationic Surfactant Solutions Due to the Growth of Wormlike Micelles. Langmuir 2005, 21, 10998-11004. [CrossRef]

50. Li, Y.; Kwak, J.C.T. Rheology and Binding Studies in Aqueous Systems of Hydrophobically Modified Acrylamide and Acrylic Acid Copolymers and Surfactants. Colloids Surf. A Physicochem. Eng. Asp. 2003, 225, 169-180. [CrossRef]

51. Hansson, P.; Lindman, B. Surfactant-Polymer Interactions. Curr. Opin. Colloid Interface Sci. 1996, 1, 604-613. [CrossRef]

52. Goddard, E.D. Interactions of Surfactants with Polymers and Proteins; Goddard, E.D., Ananthapadmanabhan, K.P., Eds.; CRC Press: Boca Raton, FL, USA, 1993; ISBN 9781315894683.

53. Asua, J.M.; Schoonbrood, H.A.S. Reactive Surfactants in Heterophase Polymerization. Acta Polym. 1998, 49, 671-686. [CrossRef]

54. Holmberg, K. Polymerizable Surfactants. Prog. Org. Coat. 1992, 20, 325-337. [CrossRef]

55. Aramendia, E.; Mallégol, J.; Jeynes, C.; Barandiaran, M.J.; Keddie, J.L.; Asua, J.M. Distribution of Surfactants near Acrylic Latex Film Surfaces: A Comparison of Conventional and Reactive Surfactants (Surfmers). Langmuir 2003, 19, 3212-3221. [CrossRef]

56. Haq, Z.; Thompson, L. Significance of Glass Transition Temperature to Polymer Latex Stabilisation by Nonionic Surfactants. Colloid Polym. Sci. 1982, 260, 212-217. [CrossRef]

57. Vijayendran, B.R.; Sawyer, L.C.; Bone, T. Effect of Surfactants on Film Formation of Poly (Vinyl Acetate) and Poly (Vinyl Acetate-Butyl Acrylate) Latexes. J. Dispers. Sci. Technol. 1982, 3, 81-97. [CrossRef]

58. Thay, P.D.; Evans, P.D. The Adhesion of an Acrylic Primer to Weathered Radiata Pine Surfaces. Wood Fiber Sci. 1998, 30, 198-204.

59. Petty, J.A.; Puritch, G.S. The Effects of Drying on the Structure and Permeability of the Wood of Abies Grandis. Wood Sci. Technol. 1970, 4, 140-154. [CrossRef]

60. Siau, J.F. Wood: Influence of Moisture on Physical Properties; Department of Wood Science and Forest Product Virginia Polytechnic Institute and State University: Blacksburg, VA, USA, 1995; ISBN 978-0962218101.

61. Abele, S.; Gauthier, C.; Graillat, C.; Guyot, A. Films from Styrene-Butyl Acrylate Lattices Using Maleic or Succinic Surfactants: Mechanical Properties, Water Rebound and Grafting of the Surfactants. Polymer 2000, 41, 1147-1155. [CrossRef]

62. de Meijer, M.; Militz, H. Moisture Transport in Coated Wood. Part 2: Influence of Coating Type, Film Thickness, Wood Species, Temperature and Moisture Gradient on Kinetics of Sorption and Dimensional Change. Holz als Roh und Werkst. 2001, 58, 467-475. [CrossRef]

63. Kocherbitov, V.; Veryazov, V.; Söderman, O. Hydration of Trimethylamine-N-Oxide and of Dimethyldodecylamine-N-Oxide: An Ab Initio Study. J. Mol. Struct. THEOCHEM 2007, 808, 111-118. [CrossRef]

64. Cogulet, A.; Blanchet, P.; Landry, V.; Morris, P. Weathering of Wood Coated with Semi-Clear Coating: Study of Interactions between Photo and Biodegradation. Int. Biodeterior. Biodegrad. 2018, 129, 33-41. [CrossRef] 
65. de Moura, L.F.; Hernández, R.E. Evaluation of Varnish Coating Performance for Two Surfacing Methods on Sugar Maple Wood. Wood Fiber Sci. 2005, 37, 355-366.

66. Baumstark, R.; Tiarks, F. Studies for a New Generation of Acrilic Binders for Exterior Wood Coatings. Macromol. Symp. 2002, 187, 177-187. [CrossRef]

67. Felton, L.A.; McGinity, J.W. Influence of Plasticizers on the Adhesive Properties of an Acrylic Resin Copolymer to Hydrophilic and Hydrophobic Tablet Compacts. Int. J. Pharm. 1997, 154, 167-178. [CrossRef]

68. Felton, L.A.; Austin-Forbes, T.; Moore, T.A. Influence of Surfactants in Aqueous-Based Polymeric Dispersions on the Thermomechanical and Adhesive Properties of Acrylic Films. Drug Dev. Ind. Pharm. 2000, 26, 205-210. [CrossRef]

69. Landry, V.; Blanchet, P.; Zotig, L.; Martel, T. Performance of Exterior Semitransparent PVDF-Acrylic Coatings. J. Coat. Technol. Res. 2013, 10, 37-46. [CrossRef]

70. Siau, J.F. Transport Prcesses in Wood; Timell, T.E., Ed.; Springer Series in Wood Science: Berlin, Germany, 1984; ISBN 978-3-642-69213-0.

71. de Meijer, M.; Thurich, K.; Militz, H. Quantitative Measurements of Capillary Coating Penetration in Relation to Wood and Coating Properties. Holz als Roh und Werkst. 2001, 59, 35-45. [CrossRef]

(C) 2020 by the authors. Licensee MDPI, Basel, Switzerland. This article is an open access article distributed under the terms and conditions of the Creative Commons Attribution (CC BY) license (http://creativecommons.org/licenses/by/4.0/). 